\title{
MEMBUAT PROGRAM REGISTRASI PASIEN DENGAN JAVA
}

\author{
NPM : 19411011 \\ NAMA : M.AJI PERDANA \\ PRODI ： Sistem Informasi \\ FAKULTAS : Fakultas Ilmu Komputer \\ EMAIL : ajicooljazz38@gmail.com
}

\section{SOAL TUGAS :}

1. Buatlah Program dengan ketentuan sebagai berikut : Input :

kode pasien $=$ PS0003

Kode Kamar $=\mathbf{4 4 4 4 4}$

Lama Menginap = 5 hari

Kode Dokter $=$ DK003

\begin{tabular}{|l|l|l|}
\hline Kode Pasien & Status Pasien & Biaya Daftar Pasien \\
\hline PS0001 & Pasien Baru & Rp. 500.000 \\
\hline PS0002 & Pasien Lama & Rp. 400.000 \\
\hline PS0003 & Pasien BPJS & Rp. 300.000 \\
\hline PS0004 & Pasien Askes & Rp. 200.000 \\
\hline
\end{tabular}

\begin{tabular}{|l|l|l|}
\hline Kode Kamar & Nama Kamar & Biaya Kamar \\
\hline 1111 & Kamar Melati & Rp. 1.000 .000 \\
\hline 2222 & Kamar Mawar & Rp. 2.000 .000 \\
\hline 3333 & Kamar Dahlia & Rp. 3.000.000 \\
\hline 4444 & Kamar Anggrek & Rp. 4.000.000 \\
\hline 5555 & Kamar Tulip & Rp. 5.000.000 \\
\hline
\end{tabular}

\begin{tabular}{|l|l|l|}
\hline Kode Dokter & Nama Dokter & Biaya Pemeriksaan \\
\hline DK001 & DR. Andi & Rp. 500.000 \\
\hline DK002 & DR. Joko & Rp. 400.000 \\
\hline DK003 & DR. Karni & Rp. 300.000 \\
\hline DK004 & DR. Amin & Rp. 200.000 \\
\hline DK005 & DR. Udin & Rp. 100.000 \\
\hline
\end{tabular}

\begin{tabular}{|l|l|}
\hline Lama Menginap & Diskon \\
\hline$>10$ Hari & $50 \%$ dari Biaya Kamar \\
\hline$>8$ Hari & $40 \%$ dari Biaya Kamar \\
\hline$>6$ Hari & $30 \%$ dari Biaya Kamar \\
\hline$>4$ Hari & $20 \%$ dari Biaya Kamar \\
\hline$>+1$ & $10 \%$ dari Biaya Kamar \\
\hline
\end{tabular}

Total Bayar $=$ Biaya Daftar Pasien + Biaya Kamar + Biaya Pemeriksaan - Diskon

Output (Tampilkan) $=$

Status Pasien

Biaya daftar Pasien

Nama Kamar 


\section{Biaya Kamar}

Nama Dokter

Biaya Pemeriksaan

Diskon

Total Bayar

\section{SOURCE CODE / KODING PROGRAM (KETIK DIBAWAH INI)}

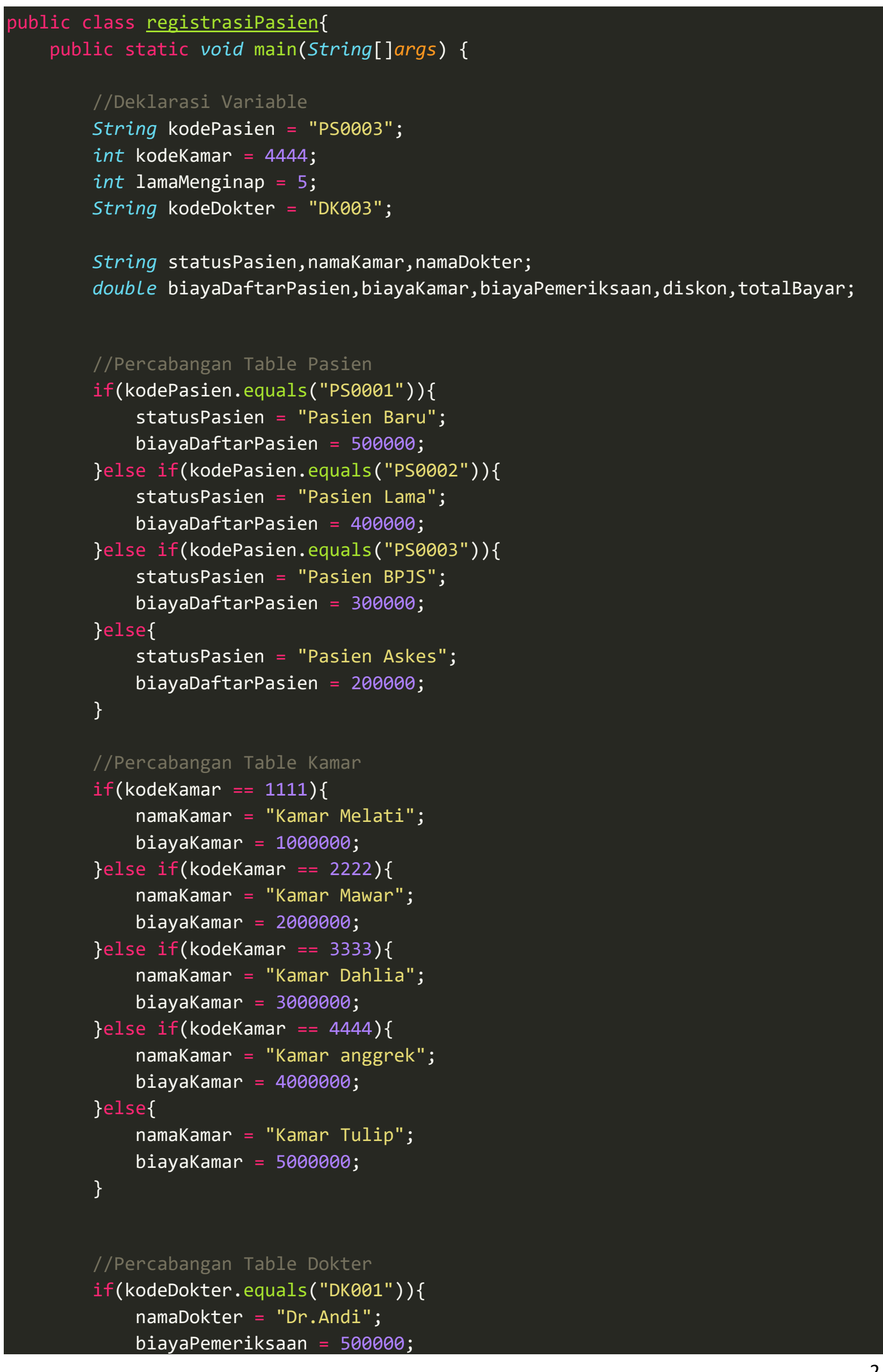




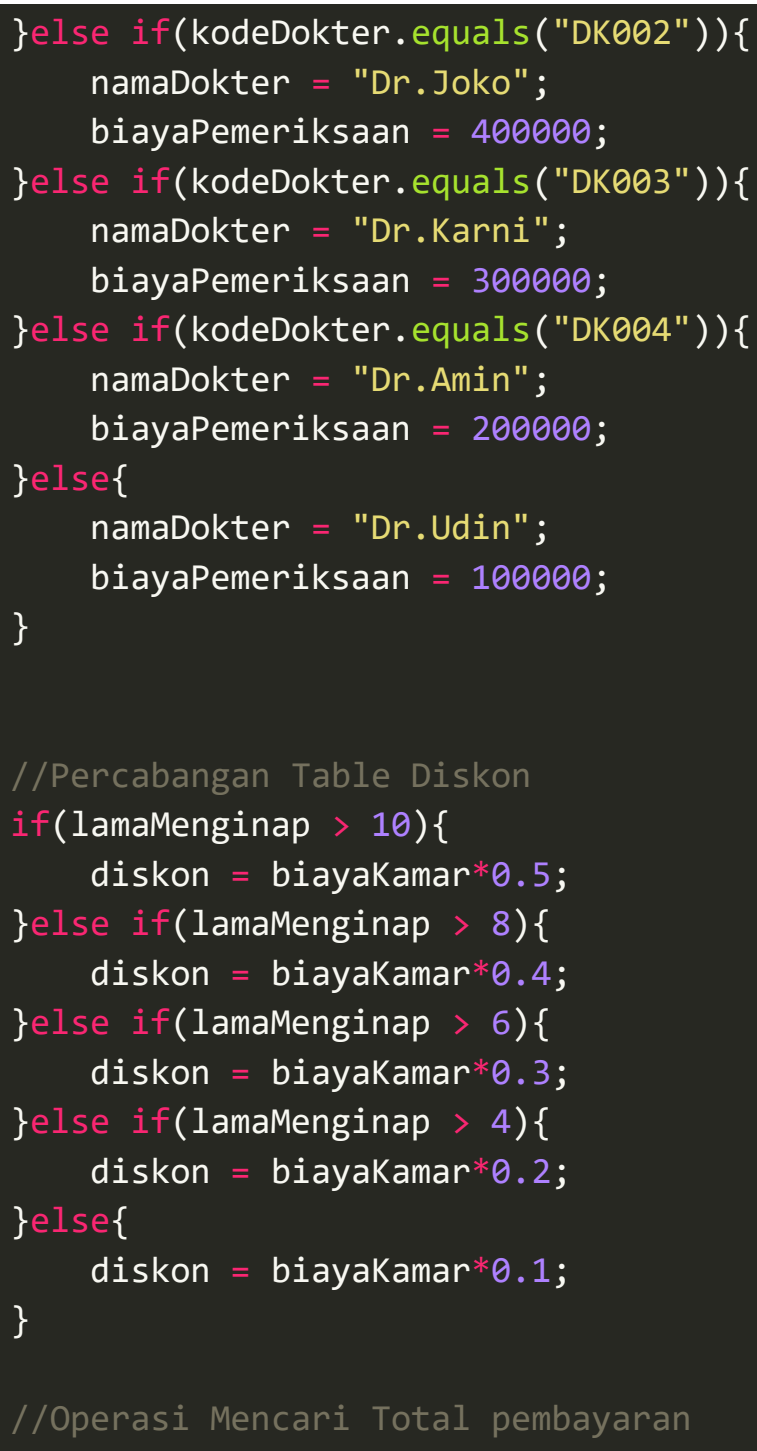




\section{PENJELASAN SOURCE CODE (KETIK DIBAWAH INI)}

\section{Public}

Merupakan sebuah modifier (ijin hak akses) pada java yang bisa di akses oleh class dan package lain.

2. Class

Adalah wadah yang berfungsi untung menampung isi dari program-program yang akan dijalankan.Nama class pada java di berikan disamping sintaks class.

\section{Contoh:}

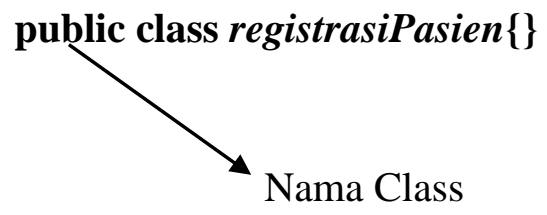

3. public static void main(String[]args)

\# public static void main

Adalah sebuah method (sekumpulan statement yang dikumpulkan bersama untuk melaksanakan tugas tertentu)dengan nama main,yang mana method ini adalah method utama untuk menjalankan suatu program.Tanpa adanya method ini program tidak akan menghasilkan apa-apa.

\section{String[]args}

String[]args adalah array (kumpulan dari variable yang menyimpan lebih dari 1 buah data yang memiliki tipe data yang sama) dengan tipe data String (tipe data yang menampung banyak karakter berupa huruf,angka dan simbol) yang berfungsi untuk menyimpan nilai argumen yang diberikan,sehingga kita bisa mengolahnya.

\section{Blog Program Java \{\}}

Blok program java merupakan tanda pembuka dari statement dan ekspresi yang di bungkus menjadi satu.Blog program java selalu di tandai dengan kurung kurawal \{\} .

\section{Contoh :}

public class registrasiPasien \{\}

Blok Pemrograman Java

\section{Penggunaan Tipe Data}

\section{\# Tipe data String}

Tipe data yang menampung banyak karakter berupa huruf,angka dan simbol. Setiap nilai dari tipe data String wajib di beri tanda petik dua ("Nilai";) untuk menandakan bahwa itu variable tersebut bernilai String.

\section{Contoh :}

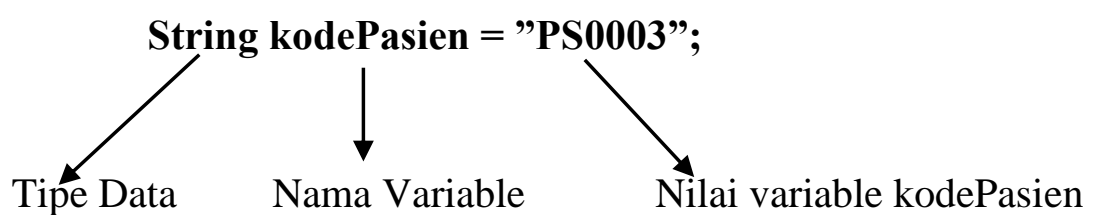

\section{\& Tipe data int (Integer)}

Tipe data yang digunakan untuk mempresentasikan bilangan bulat. 


\section{Contoh :}

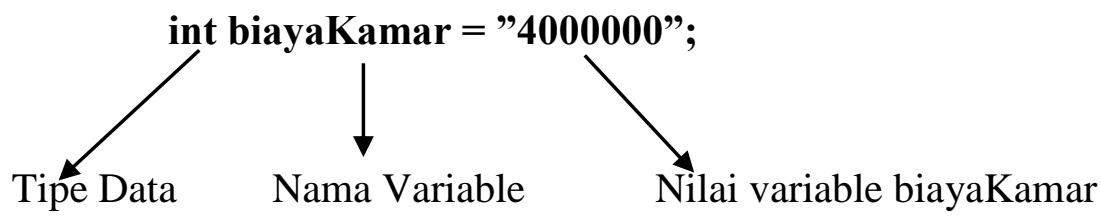

\section{\# Tipe data double}

Tipe data yang digunakan untuk mempresentasikan bilangan desimal.

\section{Contoh :}

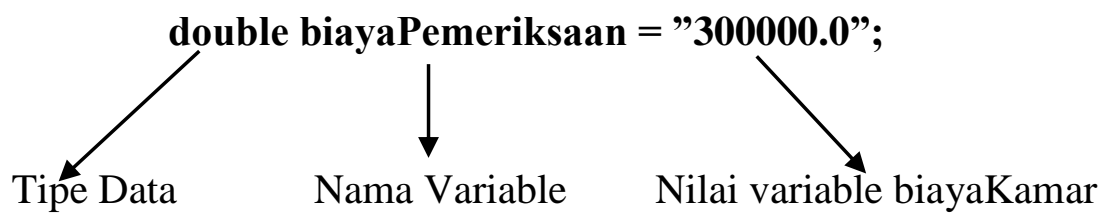

\section{Komentar Pada Java (//)}

Komentar pada java di gunakan untuk memberi keterangan pada program yang kita buat.Komentar pada java selalu di tandai dengan tanda (//).

Tanda komentar (//) tidak akan dibaca sebagai program pada java.

\section{Contoh :}

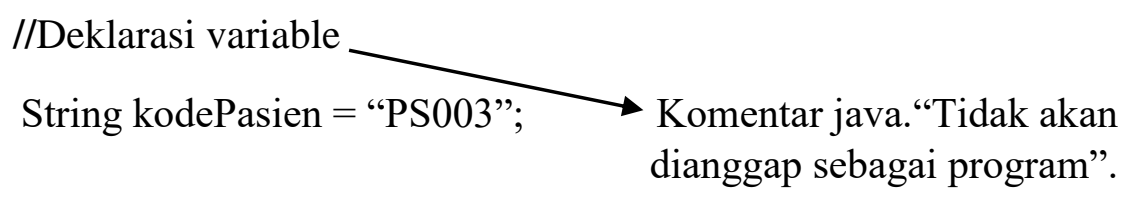

\section{Percabangan majemuk (if else if)}

Percabangan majemuk merupakan bentuk opsi atau pilihan pernyataan terkondisi yang berguna untuk pengambilan keputusan terhadap banyak kemungkinan.

\section{Contoh :}

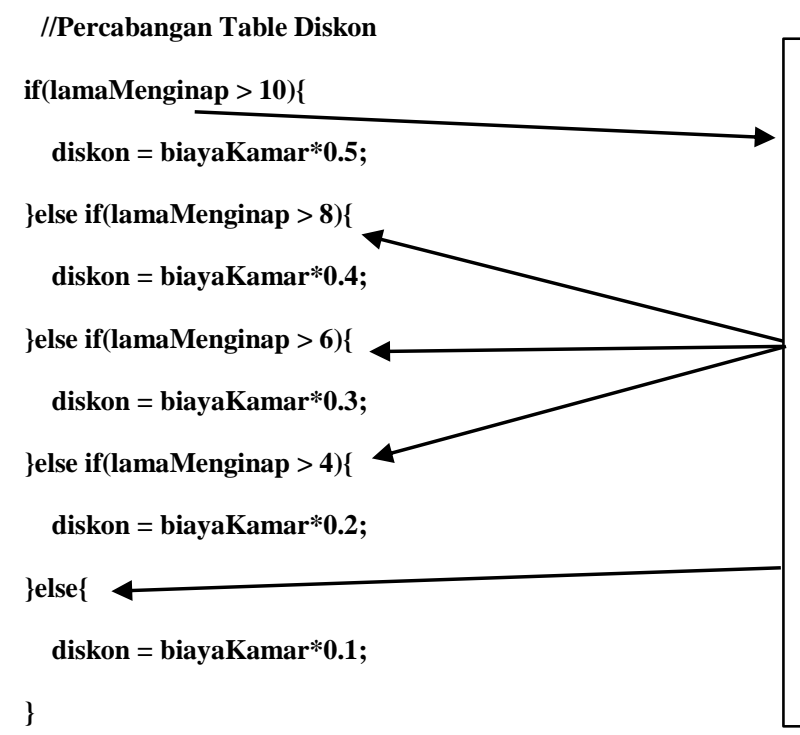

Penjelasan :

Jika lama menginap lebih dari 10 hari maka pasien akan mendapatkan diskon sebesar $50 \%$ dari biaya kamar.

Dan jika nilai variable tidak memenuhi kondisi if pertama maka akan pindah ke opsi selanjutnya,Begitupun seterusnya hingga berujung pada else.

Dan untuk fungsi else tidak perlu di beri kondisi,dikarenakan else merupakan opsi terakhir 


\section{Operasi aritmatika java}

Operator aritmatika java adalah operasi matematika yang meliputi penjumlahan (+) ,pengurangan (-) ,perkalian (*), pembagian (/) dan modulus (\%)(Sisa Hasil bagi).

\section{Contoh :}

double biayaDaftarPasien $=300000$;

double biayaKamar= 4000000;

Deklarasi Variable

double biayaPemeriksaan $=\mathbf{3 0 0 0 0 0}$;

diskon = biayaKamar*0.2;

totalBayar = biayaDaftarPasien+biayaKamar+biayaPemeriksaan-diskon;

\section{Operasi Aritmatika Java}

9. Menampilkan Output ke layar pada java.

Cara menampilkan output ke layar pada pemrograman java adalah dengan cara menggunakan perintah : System.out.println(“" ”);

println = sintaks untuk mencetak output dengan adanya penambahan baris pada kalimat berikutnya.

Print = sintaks untuk mencetak output tanpa adanya penambahan baris pada kalimat berikutnya.

\section{Contoh :}

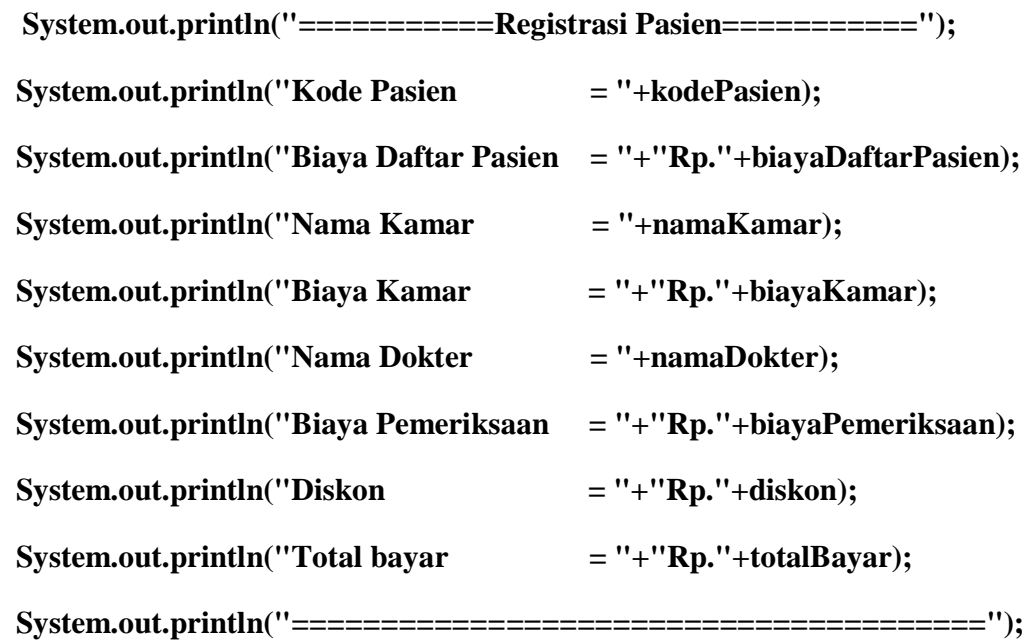

Hasil :

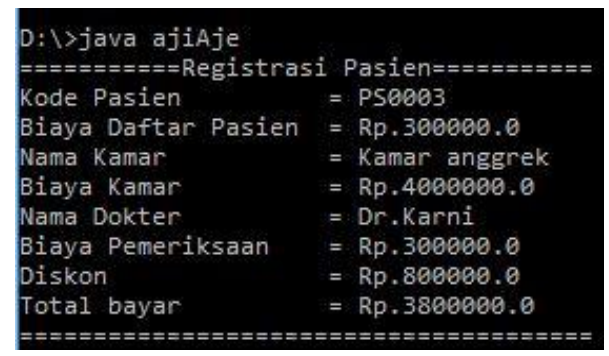




\section{FLOWCHART PROGRAM}

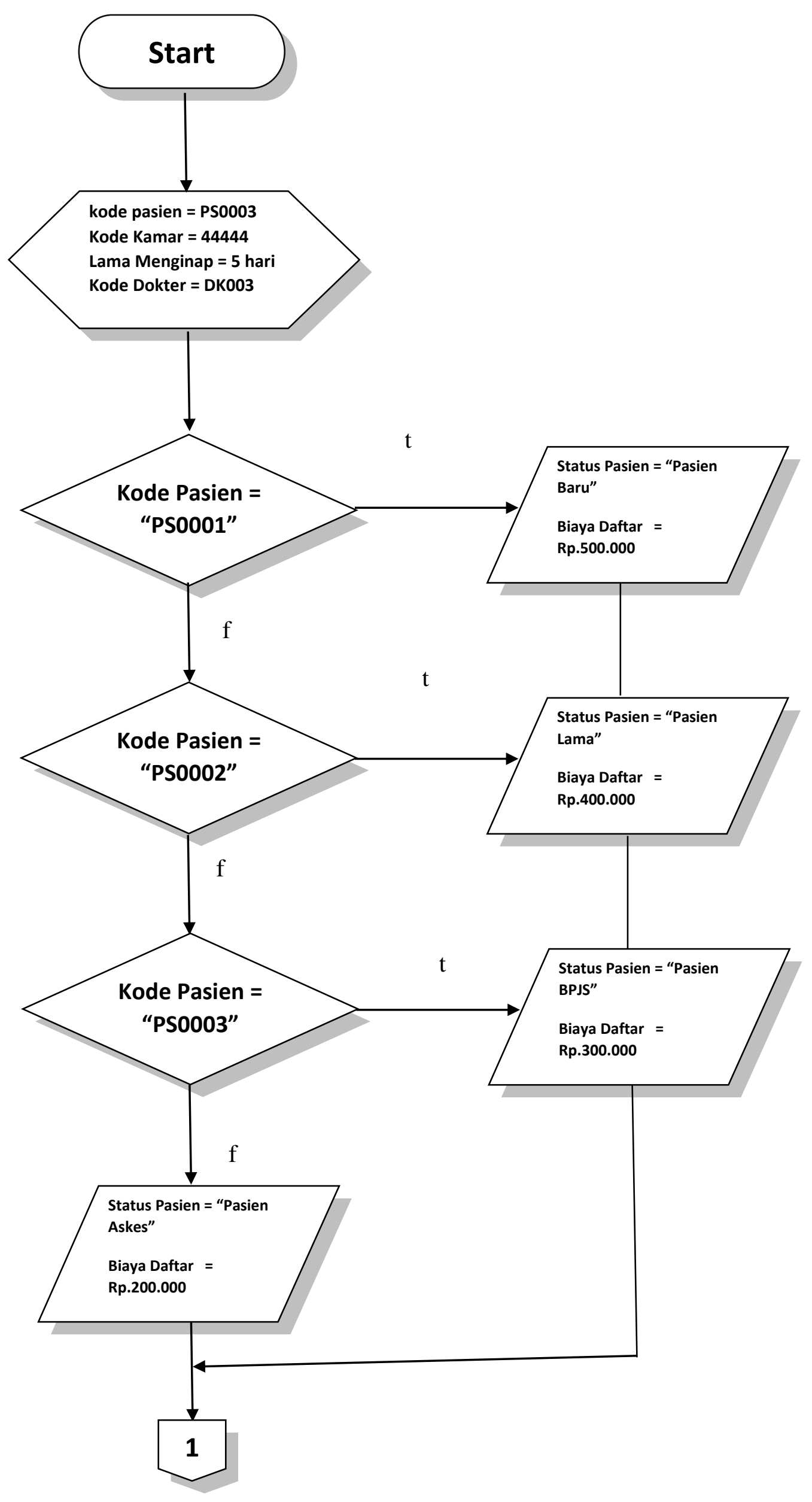




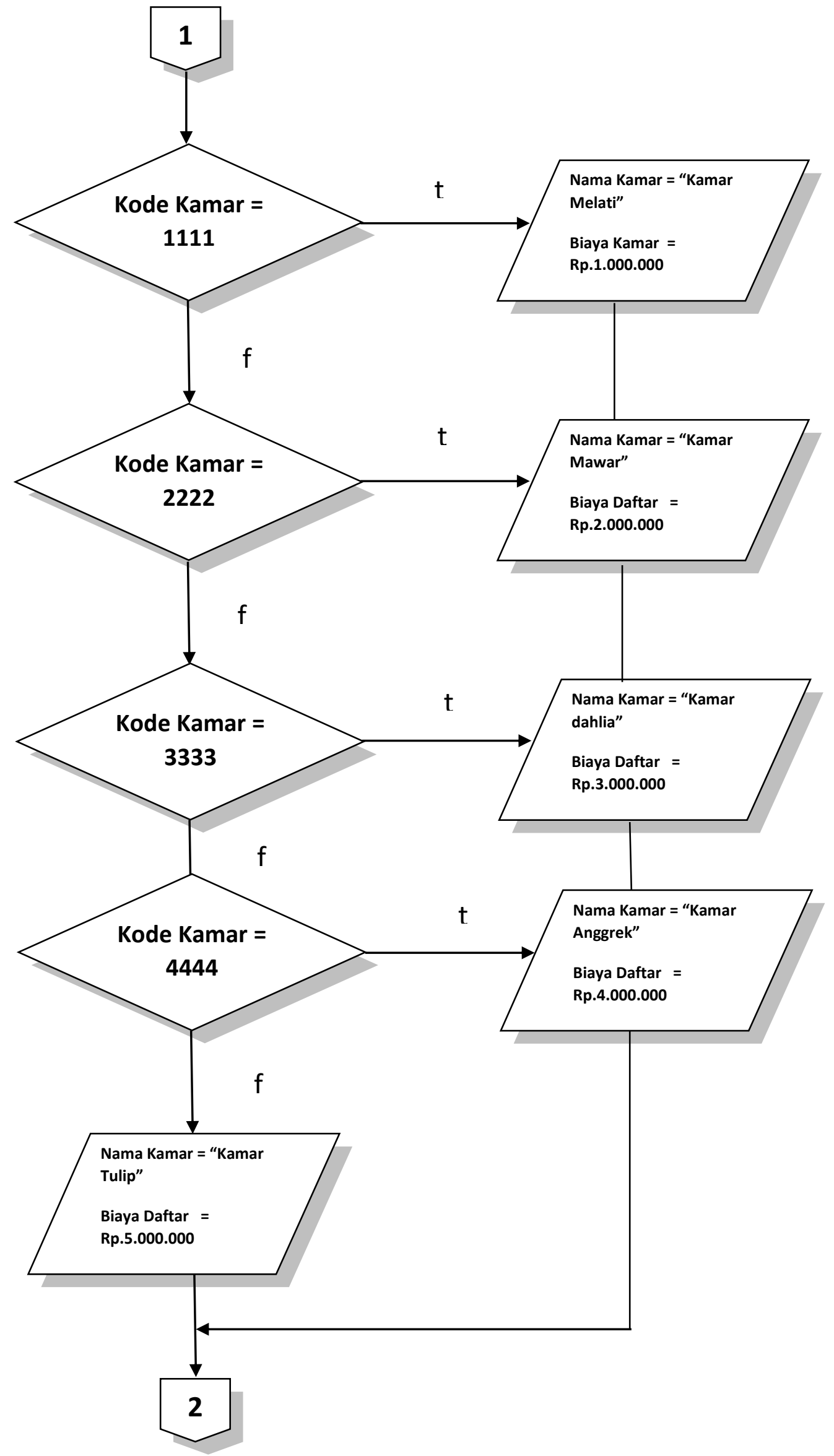




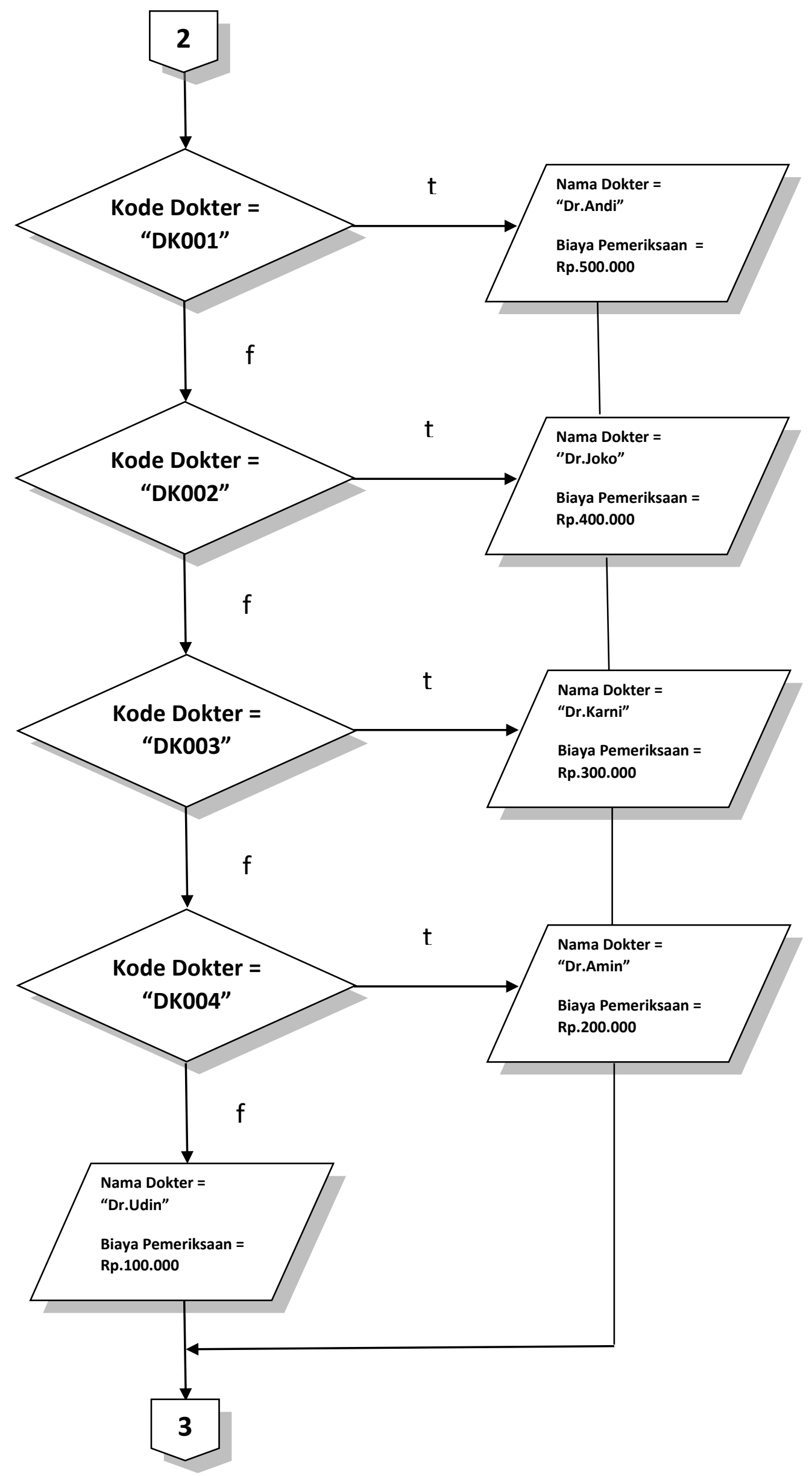




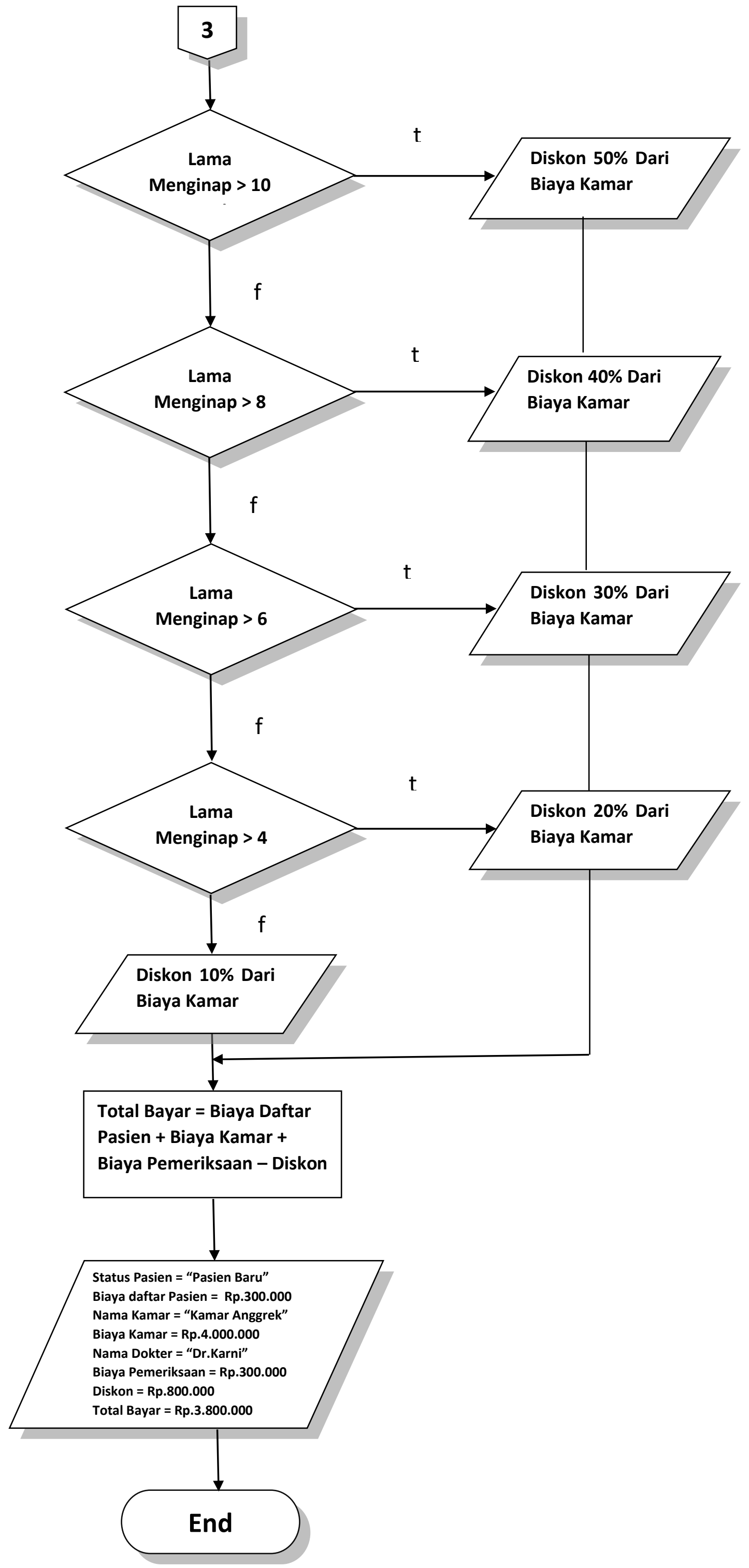


REFERENSI :

Endra, R. Y. (2019, October 29). Belajar Mudah Algoritma dan Pemograman Java. Retrieved from osf.io/v7yfn

Endra, R. Y. (2019, October 29). Internet of Things. Retrieved from osf.io/4h8sf 